\title{
The Agricultural Trait of Chinese Aesthetics and its Manifestation in Landscape
}

\author{
LIU Chengji ${ }^{1)}$
}

\begin{abstract}
Chinese aesthetics comes out of the agricultural civilization, hence the agricultural characteristics of which is the typical case to comprehend the difference between oriental and western aesthetics. First, agricultural economy is the economy of nature , from which people not only acquire means of subsistence but also entrust emotions. Second, Chinese traditional society is constructed by the principle of nature, therefore only by being integrated into the system of nature can people's behavior gets legitimacy. Third, traditional China is bound by the man-land relationship, while the immovability of the land leads to a world view that the Central Plains is the center of the world. For those reasons, man-nature relationship is the crucial issue in Chinese aesthetics. With the seasons and scenery representing time and poetic imagination forming space, Chinese aesthetics not only let the survival world be poetic, but propel landscape appreciation and garden construction into the dominant aesthetic activity of China as well.
\end{abstract}

Keywords : Chinese Aesthetics, Agriculture, Landscape, Traditional Garden

Since the period of Wang Guowei (1877-1927) and beyond, in the sphere of Chinese modern aesthetics, reconstructing tradition from modern perspectives and interpreting thereby the spiritual connotation and value of Chinese aesthetics have been the penetrating task for scholars for more than a hundred years. None the less, insofar as aesthetics originates from the West, particular difficulties are confronted with when people want to unfold the studies of the history of Chinese aesthetics. Comparatively speaking, howbeit the historical background wherein western aesthetics came into force is complicated, the commercial trade of ancient Greece and the citizen society with polis as the subject produced thereby are fundamental, which goes greatly different from Chinese social state based on agricultural civilization with village as the unit. For the part of aesthetics, the difference as such leads to the typical agricultural trait of Chinese traditional aesthetics specifically manifested as follows: first, the reliance of agricultural productive mode on nature bring the relation between man and nature to the center of concern of Chinese aesthetics. Secondly, natural materials such as soil, vegetation etc. concerned with agricultural production are the most fundamental materials employed by Chinese artistic creation. Thirdly, the reliance on the earth of agricultural production has shaped Chinese conception of time and space which is of distinctive 
aesthetic characteristics. Fourthly, nature dominates Chinese environmental cognition and landscape fancy and "moving the nature to home" is the fundamental idea of landscape design.

\section{National characteristics and artistic traits}

It is generally held that Chinese agricultural civilization originates from the Neolithic Age and the condition of the early development of this sort of civilization can be described, in manifold fashion, by virtue of Mr. Su Bingqi's words, say, "clusters of stars in the sky". Meanwhile, nevertheless, the manifold conditions are at last integrated into one, to wit. The agricultural civilization of the drainage area of the Yellow River has laid the foundation for later Chinese economy, politics and culture. As regards the shaping role played by the agricultural civilization on Chinese economic mode, political construction and view of state, it can be understood in the following aspects:

To begin with, agricultural economy is a sort of natural economy wherein nature is the object of labor, and of obtaining living materials as well. The high degree of reliance of man on nature determines the complete approval of conceptual sphere with regard to natural value. It is by reason of this that in ancient Chinese thoughts, that the Dao of heaven is natural is, be it to Confucianism or Daoism, the schools of Moism, Dialecticians or Legalism, the starting point of philosophical cognition when "integrity of heaven and man" is the common value choice. In the second place, traditional Chinese politics is a sort of natural politics, and only when man's socio-political action is put into natural order can it be of legitimacy. The political mode as such comes, plainly, from the recognition and discovery pertinent to natural law by agricultural productive mode. Take Liji . Monthly Regulations 礼记 - 月令 as an example: in the 12 months of a year, the daily as well as political actions of the king, the ministers, the people engaged in various careers and commoners are all adopted into the alternation of the four seasons, and the temporal alternation of nature offers measurement and support to the operation of human affairs. In the $18^{\text {th }}$ century, Quesnay the French Enlightenment thinker has once said, "In China, speculative science fails to progress greatly but studies as to natural law have reached a perfect stature." [2]p.57 This recourse to natural law on setting laws for human actions and the consideration of natural law as the general principle of politics are the typical characteristic of agricultural nations. In the third place, traditional China is a country limited to human-earth relation before a nation. Different from nomadic and commercial nations, the wealth (the earth) of agricultural nations are unmovable. The particularity of this sort of wealth determines the reliance of peasants on the earth, and that settling without easily moving becomes the most fundamental human-earth conception. In ancient China, that the Central Plains has long been the steady political and cultural center of Chinese nation appertains, in close fashion, to the reliance of the nation on the earth. According to the early national geographical state established by Shangshu · Yugong 尚书 • 禹贡, the realm of the Central Plains fundamentally centers at the "the emperor's reign demarcated by the Yellow River and Luo River" at the middle 
reaches of the Yellow River, extending in all directions in accordance with the arithmetic progression of “dianfu甸服”, “houfu侯服”, “suifu 绥服”, “yaofu 要服”, “huangfu荒服” ${ }^{2)}$ etc. till “the sea to the east end and desert to the west end". Some hold that this view of state or world is Central-Plain-centrism, but I contend that it is agriculture-centrism. To put it another way, the earliest developed agricultural area of China is considered as the center of the state or the world and the nearer to the center, the more civilized, the farther, the more barbarous. The differentiation between civilized and barbarous Chinese societies is not eternally unchanged. When a nation in some border area occupies the Central Plains, it may obtain political legitimacy and hence represent Chinese national civilization. This indicates that nationality is not the determinant factor to the constitution of a state; rather, the earth and agricultural productive mode are essential.

Agricultural civilization is deeply rooted in soil. The earth determines Chinese economical, political and national states, but also the attributes of beauty and arts. In the history of Chinese aesthetics and arts, the employment of the media material of soil was dominant. E.g. according to archeology, making tools is usually considered as the origin of beauty as well as man, and people position thereby, as a rule, the starting point of Chinese aesthetics at the Stone Age. In the early history of China, nevertheless, stoneware was plainly not the main laboring tool. In the area of central plains deposited by the silt from the Yellow River, stoneware is hardly available and the cumbersome stone tools are unsuitable for agricultural implantation. Contrariwise, trees qua the direct product of soil are available for making tools and suitable for the loose soil in the drainage area of the Yellow River. It is due to this that to China the agricultural nation, the earliest recorded laboring tools is not stone but wooden articles, say, Shennongshi 神农氏's “cutting the tree for ploughs, curving the tree for plows”(Yizhuan XXici Part B 易传・系辞下). In addition, according to the dating as to Chinese early history of civilization by archeology, the age (Yangshao Culture) when potteries appeared in large number in the drainage area of the Yellow River is called the Neolithic Age, which also remains to be precise. Qua the ware directly made of soil, pottery emerges on an important premise, viz. Chinese understand the attributes of soil, and this sort of understanding cannot live without agricultural civilization, either. In later ages, Chinese process with regard to soil has been increasingly delicate which in consequence makes for wonderful china. It can be said that the evolution from pottery to china shows the surmounting path of Chinese agricultural civilization from cognition of soil via practical recreation to aesthetic sublimation, but also indicates that Chinese aesthetics starts from the age of ploughs and plows, first develops in the age of pottery and gets mature in the age of china rather than that its starting point is in the so-called late Paleolithic Age or early Neolithic Age.

Identical with ordinary utensils that are based on soil and pursuit aesthetic surmounting, Chinese literature and arts are also extended from agricultural practice. For example, the “艺 (skill)"in oracle bone inscriptions originally means planting, “乐 (pleasant)” whereas expresses the pleasure for harvesting crops.[3] Another example is the character “美 (beautiful)” illustrating "large sheep is beautiful" which, apparently, has bearings on the livestock breeding in the 
agriculture of remote antiquity. In later ages, “艺”develops from agricultural planting into refined technique, i.e. “six $\operatorname{art}(\mathrm{s})$ ”, and further into spiritual “art”, “乐”from appraisal of crop harvesting into general pleasure and further into the artistic way of "music” that expresses pleasure, and “美” from clumsiness on sight and deliciousness on taste into general aesthetic appreciation. The evolution of the meaning of characters as such has embodied the advancing tendency of man from material to spiritual, from practical to aesthetic, from pleasant to aesthetic feeling on the one hand, and indicates the fundamentality of agricultural civilization for Chinese aesthetics and arts on the other. In the sphere of poetry, early Chinese poetry centers at agricultural affairs, as is said in "those who are hungry sing about food, those who labor sing about their work [via poetries]". Later they transferred, step by step, to landscape and pastoral poetries. Comparatively speaking, poetries of agricultural affairs show the trait of plainness and decorum due to their more deeply rooted in human-earth relation based on agricultural production whereas landscape and pastoral poetries are characterized by vividness and aesthetic for their formal consideration as to the countryside. On this account, it is a must to set up the idea of the general evolution from practical to aesthetic so as to understand the genesis of Chinese aesthetic consciousness and arts. In this aesthetic continuum, the steadiness and reliability provided by the earth and planting for man's subsistence are of founding significance to Chinese aesthetics and arts.

\section{Temporal experiences and spatial experiences}

According to the view of French Physiocracy, the nature participates in the productive process without asking for any reward. This selfless bestowing contributes to agricultural products' being purely "new products" [4] p.2. Apparently, that the nature is capable of realizing the bestowing as such is pertinent to the ceaseless reproducing capacity. In Chinese aesthetics, this sort of reproducing capacity of nature or the earth is given aesthetic signification in two aspects: in the first instance, nature's reproductiveness is its liveliness. This active feeling of life differentiates itself from the ossifying and mechanic western modern nature on the one hand, and is naturally of the essence of beauty thanks to its containing life on the other hand. As is said in "The great virtue between heaven and earth is called reproducing", the so-called essence of beauty is the essence of life of nature. Furthermore, natural life is forever embodied as a procedure during movement, and realizes its formal traits by dint of the blossoming and falling of flowers, the thriving and withering of grass on the earth. In this way, man's experience of the changes of natural things becomes the experience of the process of natural life. This experience enables Chinese to discover time and further take this as the regulation for human affairs. We can see from Xiaxiaozheng 夏小正, Yizhoushu.Shixunjie 逸周书 ·时训解 till historical books in later ages that the view of time of Chinese is based on the seasonal changes in agricultural sense and natural observations. Say, Xiaxiaozheng starts as follows: "In the first month, hibernated creatures wake up, migrated wild geese begin to fly back to the north, pheasants begin to chirp, and fishes begin to appear on the 
surface of the melted river. These are hints for peasants to prepare for coming fieldworks by repairing their tools." Here nature conceives time while agricultural practice regulates man's perception of time. The consciousness of time embodied in Chinese poetries in later generations is mainly of this sort of nature-dominated aroma and style. As to the work and life of people from commoners to the kings and ministers regulated by seasonal changes and solar terms, they are full of sense of rhythm plainly due to their coordination with the changes of the four seasons, and hence are adopted into a unified aestheticized natural progression.

That which is noteworthy is, nevertheless, that in the history, qua a state originating from the Central Plains and continuously keeping extending in all directions, China's conception of time regulated by calendar is not that popular. As was stated afore, Chinese ancient calendar is based on natural cognition with the warm temperate climate of the Central Plains as the standard, the reign of China however covers, from the Qin and Han Dynasties on, various climate forms like tropical, subtropical, temperate, and so on. Therefore, the agricultural calendar of the Central Plains is short of practical value to lives of nomadic, fishing and hunting nations, but also lacks instructive significance to people engaged in agriculture in non-central-plain areas. Zhang Jingzhong in the Tang Dynasty has written a poem Written at the Frontier (Bianci 边词), “In Wuyuan ${ }^{3)}$, so late comes the spring / that willows have yet to bud, even in March/ when the ice in the river here is just melting, the spring flowers in Chang'an have begun to fall, standing no touch." This poem reveals, in precise fashion, the area difference of the experience of time in the age of agriculture. Another point deserving our notice is, Chinese ancient calendar has never become manifold in accordance with area difference, and the constant standard for the establishing of the calendar is "central-plain time". The compulsive unity of this sort of calendar obtained in virtue of political power gives rise to ideological traits of time, and adds institutionalism content to the understanding of the perception of time in Chinese aesthetics.

Just like the time in ancient China centered at the Central Plains, the space then also started therefrom. The earliest geographical literature of China, Shangshu Yugong classifies, in clockwise fashion, the country into such nine states as Ji, Yan, Qing, Xu, Yang, Jing, Yu, Liang, Yong, having fundamentally outlined the geographical map of early China with the Central Plains as the center. In terms of pure space, nevertheless, there is no so-called center of the world. As is stated in Zhuangzi 庄子, “The center of the world in my view is north to Yue and south to Yan." (Zhuangzi • Under the Heaven $)^{4)}$ That the conception of the center of the world is formed mainly due to the fact that the developed agriculture in the Central Plains at the time helped people to form the reliance on the earth and hence set, in accordance with their temporal experience, where the center is and where borders are. It can be contended that the non-objectivity of the early spatial experiences of Chinese society makes for its poetic trait or aesthetic particularity, and the so-called geography hence is of poetic flavor. According to the "individual experience" purely relying on perception, the central-plain nations set the five directions of east, west, south, north and center, and adopted five colors, five pentatonic tones, five flavors and four seasons into this steady spatial structure, making 
for the circling of various aesthetic elements around the "center" of the world. The territory transgressing this empirical scope is considered, under the manipulation of the theory of cultural superiority and inferiority barbarous which, nevertheless, is imagined by aesthetic sphere as the dwelling place of immortals. Shanhaijing 山海经 (Legend of mountains and sea) is the fruit of the aesthetic imagination as such and other works from Mutianzi zhuan 穆天子传 (Legend of Emperor $\mathrm{Mu}$ in the Zhou Dynasty) via Huannanzi Zhuixingxun 淮南子. 坠形训 to Zhang Hua's Bowuzhi 博 物志 (records of legends in various aspects), on the other hand, show the path of gradual change from the actual perception as regards the Central Plains to the aesthetic imagination pertaining to remote areas. In this vein, since the central areas are definite, relevant arts usually are actual copies with distinctive realism style; peripheral areas, on the other hand, are often appealed to imagination due to their transgressing the scope of experience, and relevant artistic creations are fantastic and magnificent, full of romantic flavor, showing distinctive traits of romanticism. This view of world of Chinese with clear center but vague periphery indicates, seen at the level of aesthetics, the aesthetic system gradually passing over from empirical to imaginative, from actual to romantic.

I have said ten years before that man, time and space are the "one center, two basic points" in the sphere of aesthetics [5]p39-48. Insofar as Chinese aesthetic history is concerned, the categories that have been highly abstracted by modern science like time and space keep, under the setting of agricultural civilization, lively aesthetic traits thanks to their reliance on nature. In other words, time and space under the setting of agriculture are the time (four seasons) and space (landscape) manifested by nature, so their natural trait is their perceptibility which is also their aesthetic trait. In the mean while, when man participates in agricultural engagement, he is integrating himself into the nature or fusing his individual into the life rhythm of natural space and time. As to this sort of beauty of agricultural life constituted by man, time and space, Zong Baihua has once said, "To ancient Chinese peasants, their houses are their world. They obtain the conception of space from their houses and that of time from "Engaging in labor at sunrise and resting at sunset" (Song of Hitting the Soil). Time and space constitute their cosmos and settle their life which is leisure and rhythmic. To them, time is inseparable form space and spring, summer, autumn and winter match up east, west, south and north. This sense is manifested in the philosophical thought of the Qin and Han Dynasties. The rhythm of time (one year, twelve months, twenty four solar terms) leads the spatial directions (east, west, south, north) so as to constitute our cosmos. So our spatial perception is rhythmized and musicalized along with our temporal perception."[6]p431 It can be easily seen from this argumentation that agricultural civilization has constituted the spatiotemporal experience and directional imagination, but also input, via the interpenetration of man and nature, essential aesthetic content into human subsistence.

\section{Ideals of poetry and paintings and landscaping construction}

Tao Yuanming (A.D.365-472) is a famous poet in the middle antiquity of China. Qua an 
aristocratic descendant and a famous scholar, he has been an official in the East Jin Dynasty for 14 years. In A.D.405, drastically tired of officialdom, he began to live in seclusion under the foot of Mount. Lu (belonging to today's Jiangxi province). In the following 22 years, he has written plenty of pastoral poetries and is thus called by later generations the first pastoral poet in China.

In terms of describing rural life by dint of poetry, there are poetries of agricultural affairs and pastoral poetries in ancient China. Comparatively, howbeit the objects of description of the two sorts are identical, great difference exists with regard to the cognition of rural life. Poetries of agricultural affairs are generally authentic records of the agricultural productive activities, concerning such specific moments as sowing, harvesting etc. in a year. Hesiod's Works and Days in ancient Greece and Cato's On Agriculture in ancient Rome are of similar trait. In China, the most famous poetry of agricultural affairs is Shijing July 诗经 • 七月 in the West Zhou period which is mainly developed in the form of agricultural calendar. Compared with poetry of agricultural affairs, pastoral poetry is different, in full measure, on it treating rural life as the object of appreciation (rather than participation). Pastoral poet is an onlooker of rural life, and he treats the countryside as an aesthetic landscape wherefrom he relishes the transcendental spiritual value and significance without necessarily being engaged in agricultural labor. Tao Yuanming is both an actual participant of agricultural labor and an aesthetic onlooker, which enables his poems to reveal the trait of passing over from traditional poetry of agricultural affairs to pastoral poetry.

To Chinese classic aesthetics, Tao Yuanming's poems are of great significance in that from him Chinese art begins to realize the landscape-oriented cognition as to the countryside. The landscape cognition as such turns the countryside in poets' eyes into the pure form of beauty, representing their ideal of "poetically dwelling". Qua the artistic expressions of this sort of ideal, since the middle antiquity and beyond, pastoral and landscape poetries have become the main form of Chinese poetry and landscape, flower and bird the main objects of painting art. These poetries and paintings are incapable of, due to lacking the concrete participation in agricultural production, reflecting the hard life of peasants. This "drifting" from content to form however has effectively ensured the pure form of beauty of rural landscape. That is to say, Chinese pastoral poetry and painting in the middle antiquity are of typical Utopian trait and are the most ideal expression of the class of scholars at the time insofar as poetic life is concerned.

In ancient China, the high degree of reliance of agricultural production on natural resources gives rise to man's unconditional love for nature, and hence enables nature to be the value carrier for man. In the language of Chinese, nature is, insofar as its original meaning is concerned, is "be itself", that is, a thing is itself. Further speaking, if a thing is completely itself, this means that it has broken away from artificial processing and restricting, representing the top freedom. Here the issue of the earth bestowing man wealth during agricultural labor leads, in consequence, to the issue of "taking nature as freedom" in Chinese philosophy. Further speaking again, landscape is the illustrative revealing of nature and if nature represents the top freedom, landscape becomes the symbolic form of freedom. On this ground, we can see that in the middle antiquity of China, the 
copying and expressing of natural landscapes in pastoral poetries and paintings are not merely conveying a sort of rural fantasy; rather, they are intended to offer various copies worth following for man's ideal of free life. Here the gist of life is, it seems, not to realize spiritual addiction and intoxication in this sort of fantastic landscape but to turn the ideal of landscape expressed via poetries and paintings into reality, making "human world" into "heaven".

In China, the fruit of this sort of "turning" landscapes in paintings into reality is the landscape construction of the Ming and Qing Dynasties. Some Chinese scholars contend that landscape is, in terms of its basic intention, to "move the nature back home". On this account, we can obtain a sequence from nature to human life, viz. agriculture $\rightarrow$ nature $\rightarrow$ freedom $\rightarrow$ poetry and painting $\rightarrow$ landscape. The landscape manifestation of Chinese traditional agricultural civilization comes, in precise fashion, from the circling process from nature to art and again from art back to the reconstruction of nature.

\section{Notes}

1) Liu Chengji (1966- ), Beijing, China, professor of the School of Philosophy and Sociology in Beijing Normal University. E-Mail: liuchengjim@yahoo.com.cn

2 ) This is a sort of ancient distribution system of territory in the Xia and Zhou Dynasties. Dianfu refers to the territory with the radius of 250 kilometers, houfu refers to the territory outside the circle of dianfu with the radius of 250 kilometers more. The same holds of suifu, yaofu and huangfu in successive order.-the translator.

3 ) A county in today's Inner Mongolia.

4) Originally, Yue is the south end and Yan the north end of the territory of China at Zhuangzi's age. Here Zhuangzi means that there is no center by means of making the map in contrary way.--the translator

\section{References:}

[1] Feng Youlan. A Brief History of Chinese Philosophy [M]. Beijing: Peking University Press, 1996.

[2] François Quesnay. Chinese Imperial System [M]. Beijing: The Commercial Press, 1992.

[3] Xiu Hailin. The original meaning of “乐” and its historical evolution[J]. in The People's Music, 1986. 3.

[4] Turgot. Reflections on the Formation and Distribution of Wealth [M]. Beijing: Huaxia Publishing House, 2007.

[5] Liu Chengji. On Aesthetic Development [M]. Urumqi: Xinjiang University Press, 1997.

[6] Zong Baihua. Collected Works of Zong Baihua (Vol.2) [M]. Hefei: Anhui Education Press, 1994. 